\title{
Supplemental carnitine affects the microRNA expression profile in skeletal muscle of obese Zucker rats
}

\author{
Janine Keller*, Robert Ringseis and Klaus Eder
}

\begin{abstract}
Background: In the past, numerous studies revealed that supplementation with carnitine has multiple effects on performance characteristics and gene expression in livestock and model animals. The molecular mechanisms underlying these observations are still largely unknown. Increasing evidence suggests that microRNAs (miRNAs), a class of small non-coding RNA molecules, play an important role in post-transcriptional regulation of gene expression and thereby influencing several physiological and pathological processes. Based on these findings, the aim of the present study was to investigate the influence of carnitine supplementation on the miRNA expression profile in skeletal muscle of obese Zucker rats using miRNA microarray analysis.
\end{abstract}

Results: Obese Zucker rats supplemented with carnitine had higher concentrations of total carnitine in plasma and muscle than obese control rats $(P<0.05)$. miRNA expression profiling in skeletal muscle revealed a subset of 152 miRNAs out of the total number of miRNAs analysed (259) were identified to be differentially regulated (adjusted P-value $<0.05$ ) by carnitine supplementation. Compared to the obese control group, 111 miRNAs were up-regulated and 41 down-regulated by carnitine supplementation (adjusted P-value $<0.05$ ). 14 of these miRNAs showed a log2 ratio $\geq 0.5$ and 7 miRNAs showed a log 2 ratio $\leq-0.5$ (adjusted P-value $<0.05$ ). After confirmation by qRT-PCR, 11 miRNAs were found to be up-regulated and 6 miRNAs were down-regulated by carnitine supplementation $(P<0.05)$. Furthermore, a total of 1,446 target genes within the validated miRNAs were revealed using combined three bioinformatic algorithms. Analysis of Gene Ontology (GO) categories and KEGG pathways of the predicted targets revealed that carnitine supplementation regulates miRNAs that target a large set of genes involved in protein-localization and -transport, regulation of transcription and RNA metabolic processes, as well as genes involved in several signal transduction pathways, like ubiquitin-mediated proteolysis and longterm depression, are targeted by the miRNAs regulated by carnitine supplementation.

Conclusion: The present study shows for the first time that supplementation of carnitine affects a large set of miRNAs in skeletal muscle of obese Zucker rats suggesting a novel mechanism through which carnitine exerts its multiple effects on gene expression, which were observed during the past.

Keywords: Carnitine, microRNA expression profile, Microarray, Skeletal muscle, Obese Zucker rat

\section{Background}

Carnitine is a metabolite which is best known for its role as a shuttling molecule for the transport of long-chain fatty acids from the cytosol into the mitochondrial matrix where $\beta$-oxidation of fatty acids occurs [1]. Besides this essential function in intermediary metabolism,

\footnotetext{
* Correspondence: janine.keller@ernaehrung.uni-giessen.de Institute of Animal Nutrition and Nutritional Physiology,

Justus-Liebig-University, Heinrich-Buff-Ring 26-32, Giessen 35392, Germany
}

extensive studies over the past years revealed that supplementation with carnitine has positive effects on performance characteristics (e.g. growth rate, reproductive performance, protein:fat accretion) in livestock animals [2-6]. In addition, convincing evidence has been provided that supplemental carnitine is useful for the treatment of metabolic disorders that are associated with an impaired glucose tolerance and/or insulin sensitivity like diabetes and insulin resistance both, in model animals and in humans reviewed in [7]. With regard to the 
mechanisms underlying the beneficial effects of carnitine it has been shown that carnitine supplementation alters the expression of a large number of genes involved in important metabolic pathways, like glucose uptake and oxidation, fatty acid oxidation and protein degradation as well as critical signalling pathways, like the IGF-1/ PI3K/Akt pathway, in liver and/or skeletal muscle [8-11], which may explain at least partially the abovementioned effects in livestock and model animals and humans. However, the exact molecular mechanisms how supplemental carnitine alters gene expression in tissues are largely unknown.

Increasing evidence suggests that microRNAs (miRNAs), a class of small non-coding RNA molecules ( 22 nucleotides), play an important role in post-transcriptional regulation of gene expression and thereby influence a large number of physiological processes including differentiation, proliferation, apoptosis and immune response, but also metabolic processes, like glucose and lipid metabolism [12-14]. After maturation of the initially transcribed, socalled primary miRNAs to the single-stranded mature form, miRNAs are loaded into the RNA-induced silencing complex (RISC), which subsequently interacts with the miRNA recognition element (MRE) especially in the 3' untranslated region (3'UTR) of the corresponding mRNA (target mRNA) [13,15-17]. The kind of binding and the involved proteins determine the further fate of the target mRNAs, whose translation is either repressed or which are degraded $[18,19]$, thereby leading to downregulation of gene expression. Less commonly, miRNAs can also up-regulate gene expression [20]. Noteworthy, single miRNAs can regulate the expression of hundreds of protein coding target mRNAs and, conversely, the expression of a single gene can be regulated by multiple miRNAs, indicating the complexity of miRNA-mRNA interrelationship and the great regulatory potential of miRNAs $[13,21,22]$.

Up to now, several experiments and clinical analysis have been published demonstrating an altered miRNA expression profile and a modified phenotype due to an altered translation of target mRNAs in response to different pathologies [23-26] or pharmacologic treatment [27]. In contrast, only few studies have evaluated the influence of dietary factors, such as high-cholesterol diet [28] or conjugated linoleic acids [29], on the miRNA expression profile and its impact on gene expression in model or livestock animals. In a recent study, we could demonstrate that carnitine supplementation has beneficial effects in obese Zucker rats [30] - an established genetic model of obesity, metabolic syndrome and diabetes. The beneficial effect of carnitine supplementation was evident by the observation that the obesity-induced impairment of carnitine status and metabolic disturbances (mitochondrial dysfunction, impaired fatty acid oxidation, elevated plasma levels of triacylglycerides and non-esterified fatty acids) were significantly improved or even normalized [30]. The normalization of metabolic disturbances in obese Zucker rats due to carnitine supplementation was accompanied by an up-regulation of genes involved in carnitine uptake, fatty acid transport and uptake, $\beta$-oxidation, glucose uptake and glycolysis, and a fiber switch from type II to type I in skeletal muscle compared to non-supplemented Zucker rats [30]. In light of the important role of miRNAs for regulating gene expression, it is likely that at least some of these profound changes in gene expression in obese Zucker rats due to carnitine supplementation were mediated by altering miRNA expression in skeletal muscle. To our knowledge it has not been studied yet whether dietary carnitine influences miRNA expression. Therefore, the aim of the present study was to investigate the hypothesis that carnitine supplementation influences the miRNA expression profile in skeletal muscle of obese Zucker rats by using a miRNA microarray.

\section{Results}

\section{Growth performance}

Initial and final body weights after 28 days as well as daily body weight gains did not differ between the obese control group ( $367 \pm 11,507 \pm 18$, and $5.00 \pm 0.54$ g, respectively) and the obese carnitine group $(375 \pm 18,520 \pm 19$, and $5.18 \pm 0.34$ g, respectively) (mean $\pm S D, n=6$ ). Feed intake and feed conversion ratio also did not differ between the obese control group $(25.6 \pm 1.4 \mathrm{~g} / \mathrm{d}$ and $5.14 \pm 0.34 \mathrm{~g}$ feed/g body weight gain, respectively) and the obese carnitine group $(26.4 \pm 3.0 \mathrm{~g} / \mathrm{d}$ and $5.12 \pm 0.74 \mathrm{~g}$ feed $/ \mathrm{g}$ body weight gain) (mean $\pm S D, n=6$ ).

\section{Carnitine concentrations in plasma and skeletal muscle}

As shown in Figure 1, obese Zucker rats fed the diet supplemented with carnitine had higher concentrations of free-, acetyl- and total carnitine in plasma and skeletal muscle than those of the control group $(\mathrm{P}<0.05)$.

\section{miRNA expression profiling in skeletal muscle of obese Zucker rats}

To investigate the effect of supplemental carnitine on the muscle expression of miRNAs in obese Zucker rats, we conducted miRNA microarray analysis using miRCURY LNA ${ }^{\text {Tw }}$ microRNA Array (7th Gen). According to this miRNA profiling, 152 out of the total 259 miRNAs analyzed were identified to be differentially regulated (adjusted P-value $<0.05$ ) by carnitine supplementation. Compared to the obese control group, 111 miRNAs were up-regulated and 41 down-regulated by carnitine supplementation (adjusted P-value $<0.05$ ). Group-specific signal intensities are shown in Figure 2 and listed separately in Additional file 1: Table S1 with $\log 2$ ratios and fold 


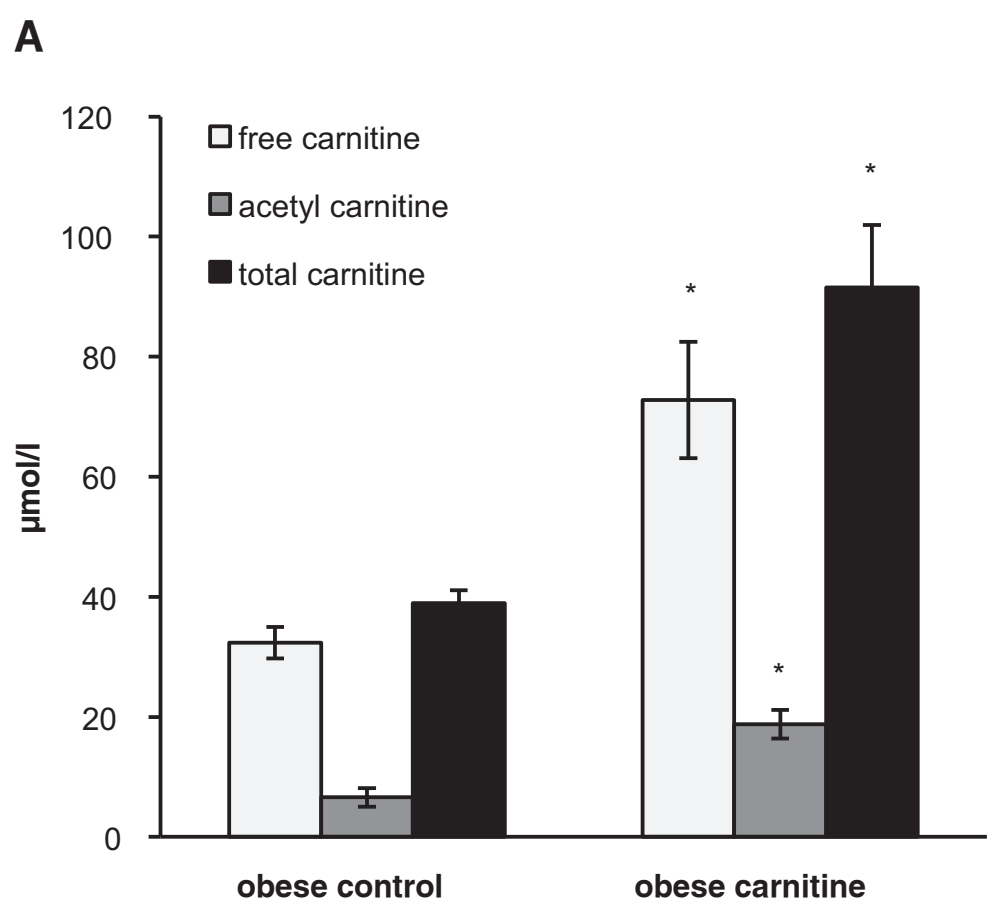

B

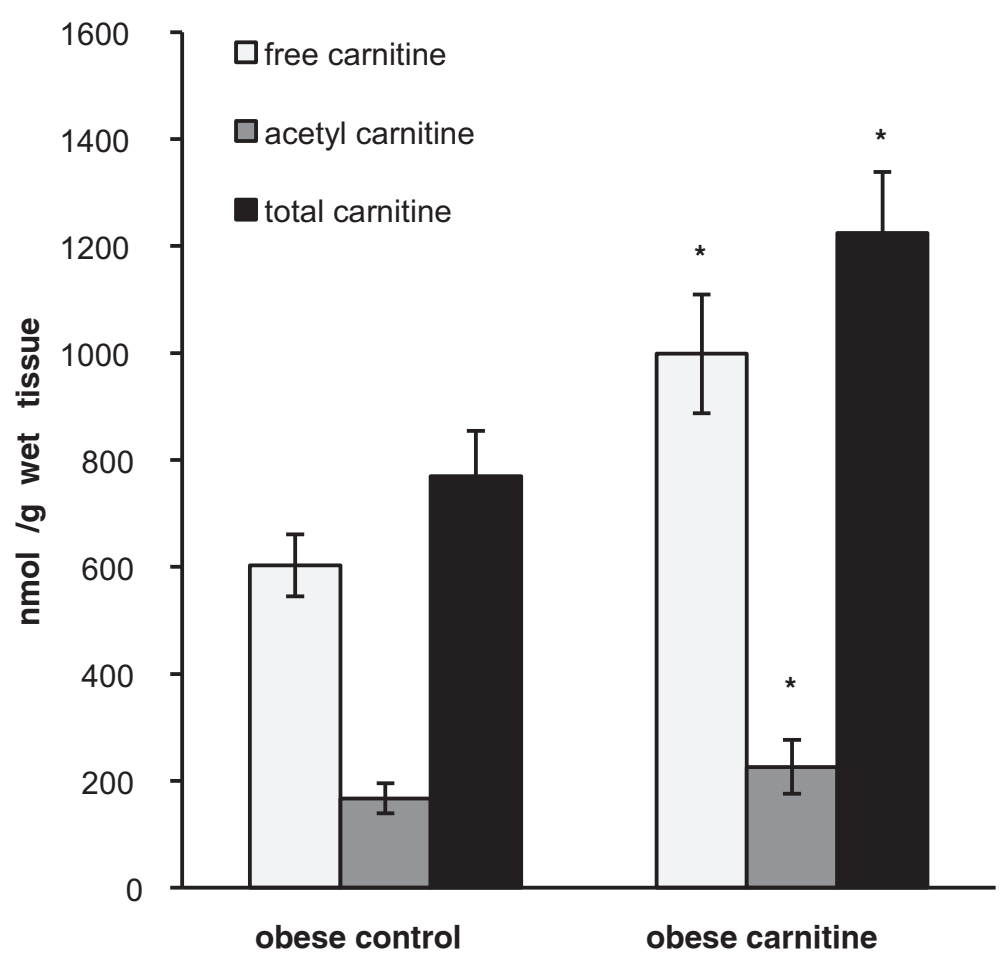

Figure 1 Concentrations of carnitine in plasma and skeletal muscle of obese Zucker rats. Concentrations of free, acetyl and total carnitine in plasma (A) and skeletal muscle (B) of obese Zucker rats fed either a control diet (obese control) or a diet supplemented with carnitine (obese carnitine). *Indicates significant difference from the obese control group $(P<0.05)$. 
Figure 2 Heat map and unsupervised hierarchical cluster analysis of the differentially expressed miRNAs in skeletal muscle of obese Zucker rats by supplemental carnitine. The clustering was provided by Exiqon Services (Denmark) and carried out using the complete-linkage method together with the euclidean distance measure. Differentially expressed miRNAs chosen with an adjusted P-value $<0.05$. Each row represents an individual miRNA and each column represents a sample. The miRNA clustering tree is shown on the left. The color scale illustrates the relative expression level of miRNAs. Red color represents an expression level below the reference channel, and green color represents expression higher than the reference. The codes on the legend are log2-transformed values.

changes. 14 of these miRNAs showed a $\log 2$ ratio $\geq 0.5$ and 7 miRNAs showed a $\log 2$ ratio $\leq-0.5$ (adjusted Pvalue $<0.05$ ). A detailed list of these miRNAs and their respective $\log 2$ ratios and fold changes as well as adjusted P-values can be found in Table 1 . The distribution of group specific signal intensities of these 21 differentially expressed miRNAs with adjusted $\mathrm{P}$-value $<0.05$ are shown in Figure 3.

\section{Validation of the most differentially expressed miRNAs by qRT-PCR}

To validate the microarray data, we performed qRT-PCR to quantify the expression of the 21 most differentially expressed miRNAs. As shown in Table 2, the expression patterns of these miRNAs detected by qRT-PCR were consistent with the microarray data. Among these 21 differentially expressed miRNAs, 17 (miR-10b-5p, miR223-3p, miR-208a-5p, miR-434-3p, miR-190a-5p, miR30d-5p, miR-347, miR-493-5p, miR-29a-5p, miR-451-5p, miR-190b-5p, miR-466c-5p, miR-883-5p, miR-466b-13p, miR-21-3p, miR-3596c, miR3584-3p) were proven significant $(\mathrm{P}<0.05)$ by $\mathrm{qRT}-\mathrm{PCR}$, one $(\mathrm{miR}-487 \mathrm{~b}-3 \mathrm{p})$ had a tendency to be significant $(P=0.06)$, and three (miR-138-2-3p, miR-1188-3p, miR-665) were not confirmed to be significant (Table 2). Only the 17 significantly validated differentially expressed miRNAs, which were proven significant by qRT-PCR, were used for the subsequent target prediction and functional analysis.

\section{Target prediction of the significantly validated} differentially expressed miRNAs and functional analysis

We performed target prediction for the 17 significantly validated differentially expressed miRNAs (shown in Table 2) to identify the influence of carnitine supplementation on potential target mRNAs in skeletal muscle of obese Zucker rats by combining the results from three online free available algorithms. According to this, a total of 868 and 578 target genes were identified for the 11 up-regulated and 6 down-regulated miRNAs, respectively. Data are shown in Additional file 2: Table S2. To elucidate the biological functions of the predicted targets 
Table 1 Most strongly up-regulated (log2 Ratio $\geq 0.5)$ and down-regulated (log2 Ratio $\leq-0.5)$ miRNAs in skeletal muscle of Zucker rats by supplemental carnitine

\begin{tabular}{|c|c|c|c|c|}
\hline ProbelD & Annotation & Log2 Ratio & FC & P-value* \\
\hline \multicolumn{5}{|c|}{ Up-regulated miRNAs } \\
\hline 148278 & Rno-miR-138-2-3p & 0.68 & 1.61 & 0.023 \\
\hline 10925 & Rno-miR-10b-5p & 0.65 & 1.57 & 0.023 \\
\hline 148261 & Rno-miR-208a-5p & 0.60 & 1.51 & 0.027 \\
\hline 14285 & Rno-miR-487b-3p & 0.60 & 1.51 & 0.023 \\
\hline 11024 & Rno-miR-223-3p & 0.59 & 1.51 & 0.023 \\
\hline 11246 & Rno-miR-434-3p & 0.54 & 1.45 & 0.049 \\
\hline 27536 & Rno-miR-190a-5p & 0.54 & 1.45 & 0.033 \\
\hline 19596 & Rno-miR-30d-5p & 0.52 & 1.43 & 0.027 \\
\hline 42763 & Rno-miR-347 & 0.52 & 1.43 & 0.023 \\
\hline 148059 & Rno-miR-493-5p & 0.51 & 1.43 & 0.023 \\
\hline 145638 & Rno-miR-29a-5p & 0.51 & 1.43 & 0.023 \\
\hline 42866 & Rno-miR-451-5p & 0.51 & 1.42 & 0.037 \\
\hline 148417 & Rno-miR-1188-3p & 0.51 & 1.42 & 0.023 \\
\hline 42472 & Rno-miR-190b-5p & 0.50 & 1.42 & 0.023 \\
\hline \multicolumn{5}{|c|}{ Down-regulated miRNAs } \\
\hline 42586 & Rno-miR-466c-5p & -0.51 & -1.42 & 0.023 \\
\hline 42462 & Rno-miR-883-5p & -0.51 & -1.43 & 0.023 \\
\hline 148483 & Rno-miR-466b-1-3p & -0.55 & -1.46 & 0.023 \\
\hline 148583 & Rno-miR-3584-3p & -0.62 & -1.54 & 0.041 \\
\hline 42770 & Rno-miR-665 & -0.64 & -1.55 & 0.027 \\
\hline 148139 & Rno-miR-3596c & -0.73 & -1.66 & 0.027 \\
\hline 17896 & Rno-miR-21-3p & -0.78 & -1.72 & 0.023 \\
\hline
\end{tabular}

*P-values have been corrected for multiple testing by the Benjamini and Hochberg adjustment method.

we carried out gene-term enrichment analysis using Gene Ontology (GO) categories and Kyoto Encyclopedia of Genes and Genomes (KEGG) pathway analysis by using the DAVID Functional Annotation Chart tool separately for the targets identified for the 11 up- and 6 down-regulated miRNAs.

Gene-term enrichment analysis within GO category "biological process" revealed that most target genes predicted from the 11 up-regulated miRNAs were involved in protein localization, cell adhesion, biological adhesion, protein transport and establishment of protein localization (Figure $4, \mathrm{P}<0.01)$. In contrast, most target genes predicted from the 6 down-regulated miRNAs were involved in "biological processes" dealing with regulation of transcription, regulation of RNA metabolic process, as well as regulation of transcription, DNA dependent (Figure 5, $\mathrm{P}<0.01$ ). Within the GO category "molecular function", most of the target genes predicted from the 11 upregulated miRNAs were involved in enzyme- and RNAbinding and in cytoskeletal protein binding (Figure 4,
$\mathrm{P}<0.01$ ), while most of the targets from the 6 downregulated miRNAs had functions in ion-, metal ion- and cation-binding, as well as nucleotide binding (Figure 5, $\mathrm{P}<0.01$ ). Regarding the GO category "cell component", the greatest number of targets predicted from the 11 up-regulated miRNAs had functions associated with cell projection (Figure 4, $\mathrm{P}<0.01$ ), whereas the functions of the targets predicted from the 6 down-regulated miRNAs were associated with plasma membrane (Figure 5, $\mathrm{P}<0.01$ ).

Gene-term enrichment analysis of the targets predicted from the significantly validated most differentially expressed miRNAs using KEGG pathways revealed several enriched regulatory pathways. As shown in Table 3, enriched KEGG pathways (EASE score $<0.05$ ) for the 868 putative mRNAs from the 11 up-regulated miRNAs included pathways regulating cancer, the Wnt signalling pathway, ubiquitin mediated proteolysis, leukocyte transendothelial migration, adherens junction, longterm depression and ether lipid metabolism, and for the 578 putative targets from the 6 down-regulated miRNAs pathways regulating ubiquitin mediated proteolysis, leukocyte transendothelial migration, $\mathrm{T}$ cell receptor signalling and long-term depression (Table 3).

\section{Validation of selected predicted target genes by qRT-PCR}

To explore whether the differentially expressed miRNAs were associated with changes in the mRNA levels of respective target genes, we determined relative mRNA levels of one selected potential target gene for each validated miRNA by qRT-PCR. As shown in Table 4, the relative mRNA levels of predicted targets (UBE2A, HERC2, ARPC5, GNAI2, SLC6A8, IGF-1, ITPR1, ACSL3, and SALL3) of 9 differentially regulated miRNAs were significantly regulated by carnitine in the opposite direction $(\mathrm{P}<0.05)$, whereas the relative mRNA levels of the predicted targets of the remaining differentially regulated miRNAs were not significantly inversely regulated.

\section{IGF-1 protein level in skeletal muscle}

To further investigate whether the carnitine-induced increase in the mRNA level of IGF-1, a putative target gene of miR-466b-1-3p but also miR-208a-5p, is also associated with an increase in the protein level of IGF-1, we determined protein levels of IGF-1 in skeletal muscle of the obese Zucker rats. Consistent with the higher mRNA level of IGF-1, the relative protein level of IGF-1 was increased by $35 \%$ in the obese carnitine group compared to the obese control group (Figure $6, \mathrm{P}<0.05$ ).

\section{Discussion}

This is the first study demonstrating the response of the miRNA expression profile to dietary supplementation 


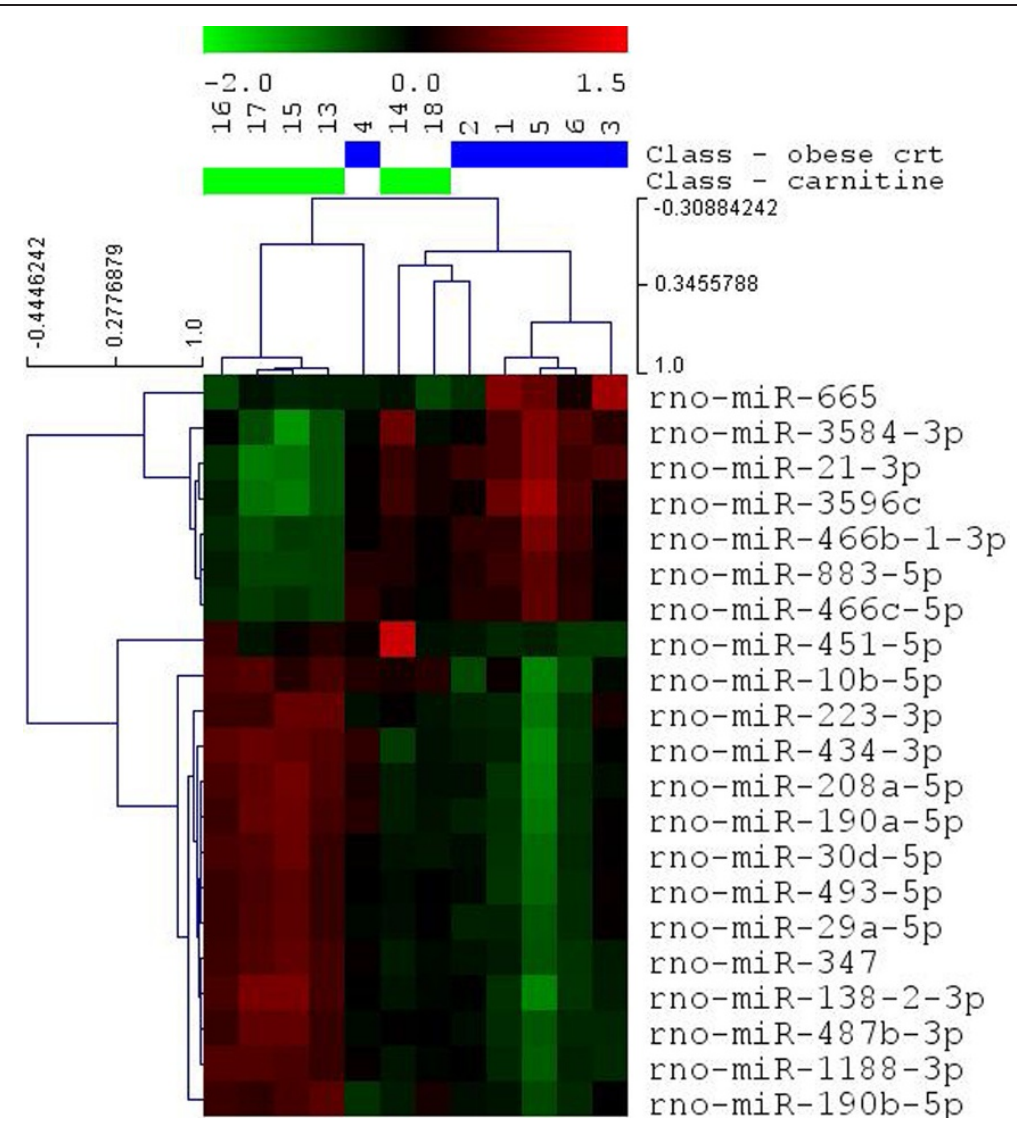

Figure 3 Heat map and unsupervised hierarchical cluster analysis of the most strongly differentially expressed miRNAs in skeletal muscle of obese Zucker rats by supplemental carnitine. The clustering was provided by Exiqon Services (Denmark) and carried out using the complete-linkage method together with the euclidean distance measure. Most strongly differentially expressed miRNAs chosen with a log2 Ratio $\geq 0.5$ and $\leq-0.5$ and an adjusted P-value $<0.05$. Each row represents an individual miRNA and each column represents a sample. The miRNA clustering tree is shown on the left. The color scale illustrates the relative expression level of miRNAs. Red color represents an expression level below the reference channel, and green color represents expression higher than the reference. The codes on the legend are log2-transformed values.

with carnitine. miRNAs represent a relatively newly identified class of small non-coding RNA molecules which play an important role for gene expression by mainly downregulating the expression of protein-coding genes, and, consequently influence both, physiological and pathological processes. Since the molecular mechanisms underlying changes in gene expression by carnitine supplementation in livestock and model animals are only poorly understood, the present study aimed to elucidate possible alterations in the miRNA profile following dietary supplementation with carnitine. For miRNA profiling, we used skeletal muscle samples from carnitine-supplemented and control (nonsupplemented) obese Zucker rats, in which we have recently reported profound changes in the expression of genes involved in important metabolic pathways, like glucose and fatty acid metabolism and protein degradation [30]. It is well known that the carnitine status in obese Zucker rats and other models of genetic and diet-induced obesity is markedly impaired and as a consequence several metabolic disturbances are induced [31-33]. In contrast, supplementation with carnitine improves carnitine status, which was also demonstrated in the present study, and reverses to a great part these metabolic disturbances, like elevated blood levels of triacylglycerides and non-esterified fatty acids, glucose intolerance and insulin resistance $[30-32,34]$. The key finding of the present study is that carnitine supplementation resulted in a profound change in the miRNA expression profile in skeletal muscle of obese Zucker rats suggesting a novel regulatory mechanism by which dietary carnitine alters gene expression and mediates at least some of its biological effects. According to our miRNA microarray analysis, a total of 152 miRNAs were identified to be differentially expressed, 111 being upregulated and 41 being down-regulated, in skeletal muscle of the obese Zucker rats in response to carnitine supplementation. In order to elucidate the functional implications of alterations in the miRNA profile it is a widely accepted approach to identify the miRNA target genes by employing specific bioinformatics tools. Because one single miRNA can regulate the expression of hundreds of target mRNAs, 
Table 2 Validation of microarray results using qRT-PCR

\begin{tabular}{|c|c|c|c|c|}
\hline \multirow[b]{2}{*}{ miRNAs } & \multicolumn{2}{|c|}{ Mean fold changes } & \multicolumn{2}{|c|}{ P-value* } \\
\hline & microarray & qRT-PCR & microarray & qRT-PCR \\
\hline miR-138-2-3p & 1.61 & 1.07 & 0.023 & 0.676 \\
\hline miR-10b-5p & 1.57 & 1.58 & 0.023 & 0.023 \\
\hline miR-487b-3p & 1.51 & 1.26 & 0.023 & 0.060 \\
\hline miR-223-3p & 1.51 & 1.59 & 0.023 & 0.015 \\
\hline miR-208a-5p & 1.51 & 4.26 & 0.027 & 0.001 \\
\hline miR-434-3p & 1.45 & 1.85 & 0.049 & 0.017 \\
\hline miR-190a-5p & 1.45 & 1.50 & 0.033 & 0.016 \\
\hline$m i R-30 d-5 p$ & 1.43 & 1.53 & 0.027 & 0.035 \\
\hline miR-347 & 1.43 & 1.52 & 0.023 & 0.048 \\
\hline miR-493-5p & 1.43 & 1.64 & 0.023 & 0.001 \\
\hline miR-29a-5p & 1.43 & 1.49 & 0.023 & 0.047 \\
\hline$m i R-451-5 p$ & 1.42 & 1.63 & 0.037 & 0.034 \\
\hline miR-1188-3p & 1.42 & 1.12 & 0.023 & 0.500 \\
\hline miR-190b-5p & 1.42 & 1.74 & 0.023 & 0.021 \\
\hline $\operatorname{miR}-466 c-5 p$ & -1.42 & -1.49 & 0.023 & 0.021 \\
\hline miR-883-5p & -1.43 & -2.28 & 0.023 & 0.005 \\
\hline miR-466b-1-3p & -1.46 & -1.76 & 0.023 & 0.011 \\
\hline miR-21-3p & -1.72 & -2.04 & 0.023 & 0.001 \\
\hline miR-3596c & -1.66 & -2.33 & 0.027 & 0.004 \\
\hline miR-665 & -1.55 & -1.22 & 0.027 & 0.140 \\
\hline miR-3584-3p & -1.54 & -2.78 & 0.041 & 0.003 \\
\hline
\end{tabular}

*P-values have been corrected for multiple testing by the Benjamini and Hochberg adjustment method.

while one gene may be targeted by many miRNAs, target prediction is usually carried out only in a small subset of the differentially expressed miRNAs, typically in the most strongly differentially regulated miRNAs. Following this approach, we selected those miRNAs, which were significantly differentially expressed between the two groups at a $\log 2$ ratio of $\geq 0.5$ and $\leq-0.5$ according to microarray analysis and according to qRT-PCR, resulting in 11 up-regulated and 6 down-regulated miRNAs, respectively. The subsequent in silico-target mRNA prediction revealed 868 and 578 target genes for the 11 up-regulated and the 6 downregulated miRNAs, respectively. Due to the limited conclusiveness of in silico-predictions, we determined mRNA levels of one individual target gene for each of the carnitine-regulated miRNAs using GRT-PCR in order to provide some proof of concept that predicted targets are indeed regulated in the expected direction in vivo. According to this, we observed that the majority of predicted target mRNAs of the differentially regulated miRNAs were regulated by carnitine in the opposite direction indicating that the predictions from in silico-analysis are reliable at least in some instances. One of the predicted miRNA-mRNA interactions, which could be confirmed in vivo, concerns the insulin-like growth factor (IGF)-1. IGF-1 is a known target of the down-regulated miR-466b-1-3p and has been demonstrated to be up-regulated by carnitine in the present study but also in previous studies [11,35]. In order to strengthen the biological relevance of miRNA-mRNA interactions for regulating gene expression by carnitine in the case of IGF-1, we also determined protein levels of IGF-1. In line with the elevated mRNA level of IGF-1 in skeletal muscle, we also observed increased protein levels of IGF-1 in skeletal muscle of rats of the carnitine group. This suggests that the elevated mRNA level of IGF-1 is a result of a decreased repressive activity of the down-regulated miR466b-1-3p and that miRNA-mRNA interactions indeed play a significant role in mediating biological effects of carnitine. One important reason that might explain that the predictions of target mRNAs for differentially regulated miRNAs are not reliable in all instances is that one gene is normally subject to regulation by a cluster of miRNAs, from which certain miRNAs can be regulated in the opposite direction. Another reason might be that the carnitinemediated change in the expression of certain miRNAs was not strong enough to induce a significant change in the expression of the targeted mRNAs. Moreover, posttranscriptional modifications by carnitine might also be responsible for the observation that predicted miRNAmRNA interactions are not visible in vivo. Finally, we carried out gene-term enrichment analysis within the three GO categories and the KEGG pathway database using DAVID software, separately for the targets identified from the prediction of the 11 up- and 6 down-regulated miRNAs in order to identify biological functions of the predicted targets.

Noteworthy, gene-term enrichment analysis of the targets predicted from the differentially regulated miRNAs revealed that carnitine supplementation regulates miRNAs that target a large set of genes involved in enzymeand RNA-binding, regulation of transcription, regulation of transcription-DNA dependent, regulation of RNA metabolic process, and nucleotide-binding. This clearly indicates that carnitine supplementation regulates many genes which are involved in controlling gene expression and that gene regulation by carnitine supplementation is more complex due to miRNA-mRNA interactions than previously thought. Amongst the predicted target mRNAs of the regulated miRNAs we found about 60 mRNAs encoding transcription factors, which were classified according to their function into general and specific transcription factors (not shown). We found that the main part belonged to the class specific transcription factors, like ATF3, BCL6, BCOR, BHLHE23, BHLHE41, CREM, E2F6, ELK4, HBP1, HIVEP1, IRF9, JUN, KLF15, MEF2C and many others. These specific transcription factors usually bind upstream of the initiation site to specific recognition sequences of the regulated gene to 


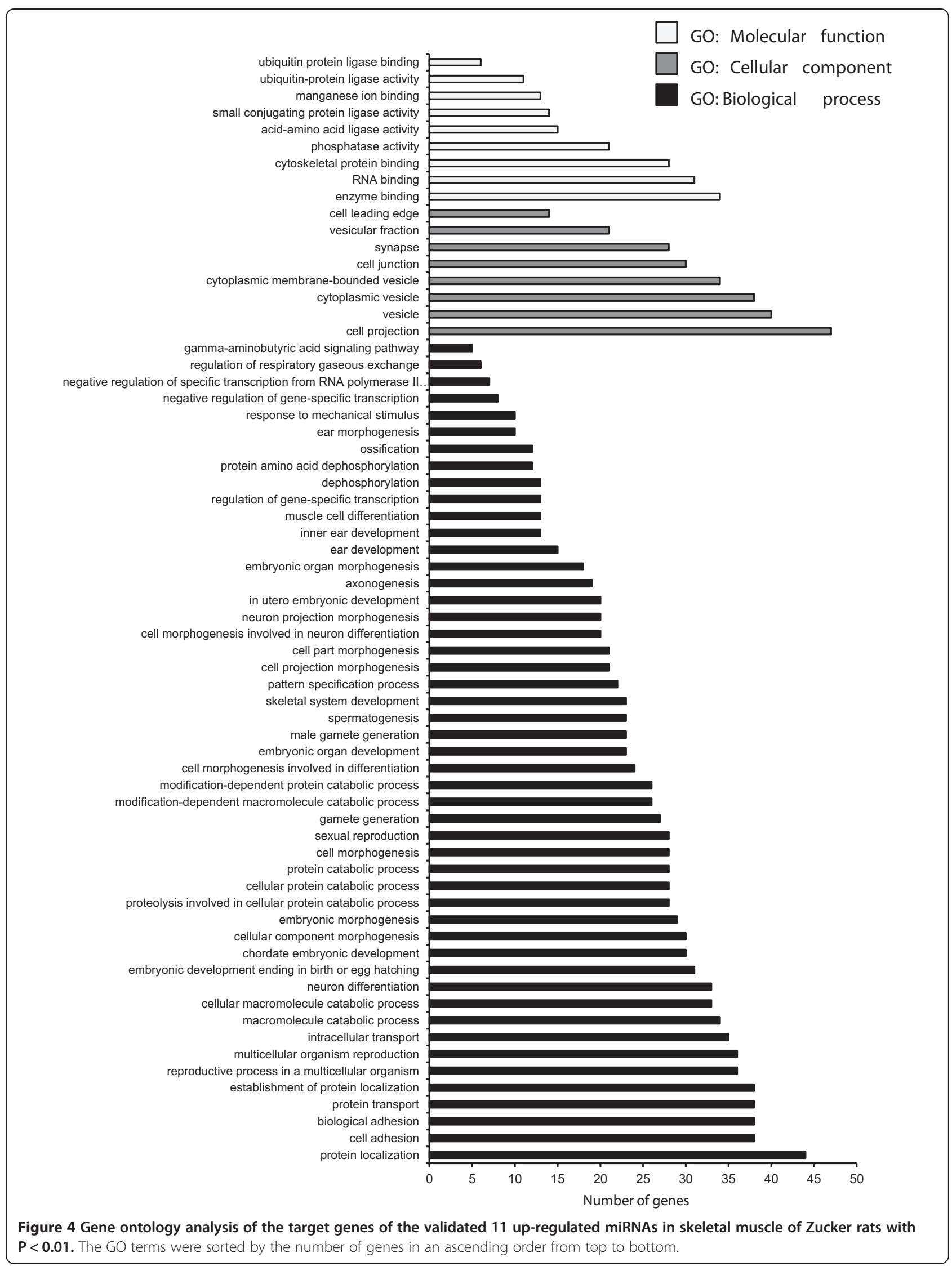




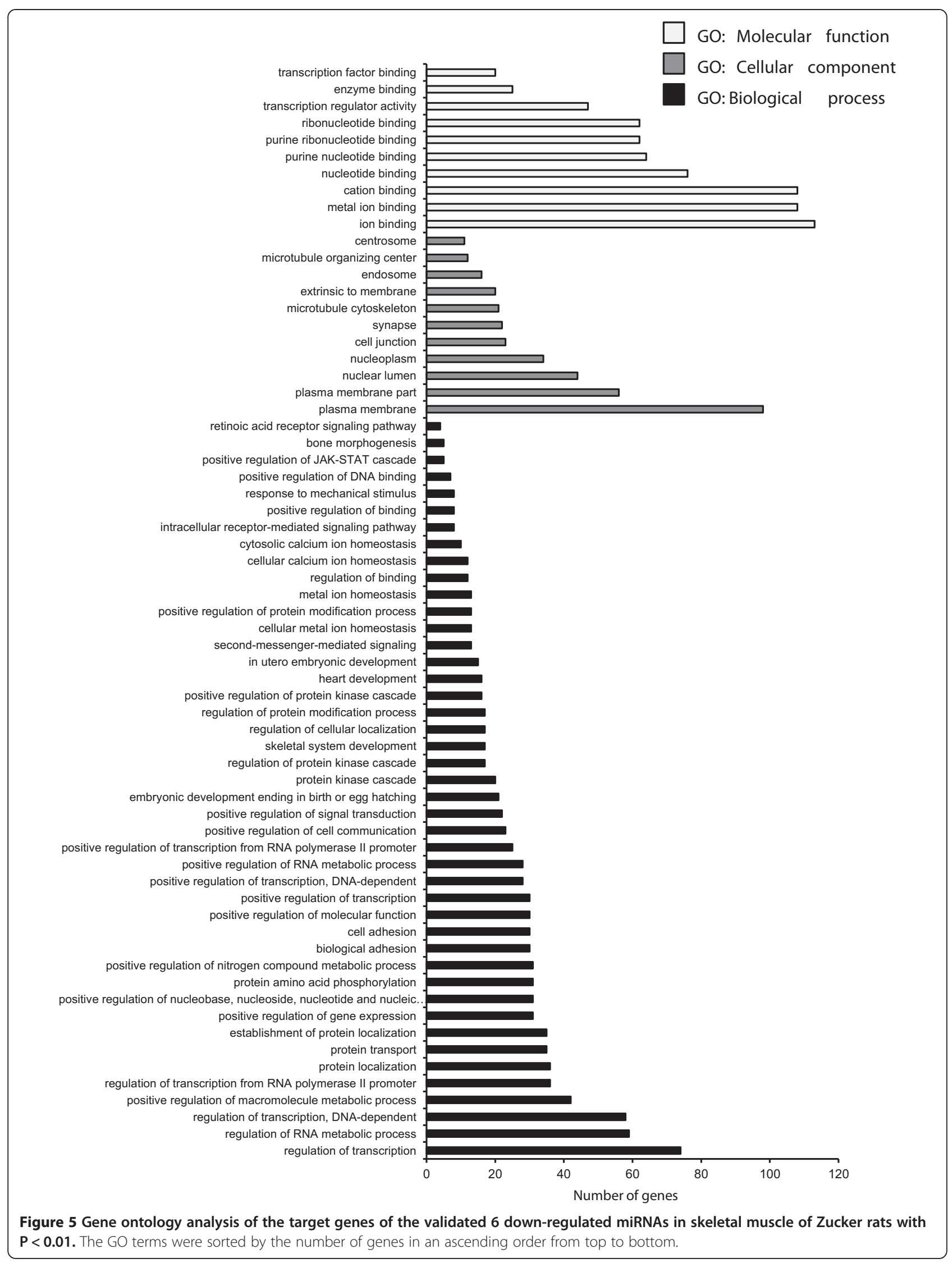


Table 3 KEGG pathway analyses of the predicted target genes of the validated most differentially expressed microRNAs with $\mathrm{P}<0.05$

\begin{tabular}{|c|c|c|}
\hline Pathway & P-value & Genes \\
\hline \multicolumn{3}{|l|}{ Putative targets of the up-regulated miRNAs } \\
\hline Athways in cancer & 0.044 & $\begin{array}{l}\text { WNT5A, TCF7, FGFR3, RALBP1, VHL, TGFBR1, IGF1, CTNNA1, STK4, } \\
\text { ITGB1, IGF1R, CBLB, CCND1, HIF1A, CDKN1B, JUN, SOS2, HHIP, WNT9A, PIAS1 }\end{array}$ \\
\hline Wnt signalling pathway & 0.012 & $\begin{array}{l}\text { WNT5A, TBL1XR1, TCF7, ROCK2, PPP2R5D, DKK2, CCND1, SIAH1A, } \\
\text { JUN, CAMK2B, WNT9A, PPP3CA, FBXW11 }\end{array}$ \\
\hline Ubiquitin mediated proteolysis & 0.011 & CUL3, UBE2N, UBE2A, CBLB, UBE3A, VHL, UBE2K, SIAH1A, UBE2I, HERC2, PIAS1, FBXW11 \\
\hline Leukocyte transendothelial migration & 0.037 & GNAI2, ACTN4, ROCK2, CXCR4, RAP1A, RAPGEF4, CTNNA1, ITGB1, CLDN23, PTPN11 \\
\hline Adherens junction & 0.026 & IGF1R, PVRL4, TCF7, TJP1, ACTN4, TGFBR1, CTNNA1, SNAI1 \\
\hline Longterm depression & 0.048 & IGF1R, GNAI2, PLA2G12A, GRID2, IGF1, PRKG2, ITPR2 \\
\hline Ether lipid metabolism & 0.044 & PLA2G12A, PLA2G7, PAFAH1B1, PPAP2A, PPAP2B \\
\hline \multicolumn{3}{|c|}{ Putative targets of the down-regulated miRNAs } \\
\hline Ubiquitin mediated proteolysis & 0.003 & CUL3, UBE2N, UBE3A, VHL, RHOBTB2, BIRC6, UBA6, UBE2I, SMURF2, UBE2D1, CUL1 \\
\hline Leukocyte transendothelial migration & 0.017 & CLDN8, ITK, CLDN19, PIK3CA, RAPGEF4, CLDN11, ITGB1, MLLT4, PRKCB \\
\hline T cell receptor signalling pathway & 0.036 & ITK, JUN, PIK3CA, CHP, DDAH1, NFATC3, LCP2, IL2 \\
\hline Long-term depression & 0.042 & GNAO1, IGF1, GUCY1B3, GRM1, ITPR1, PRKCB \\
\hline
\end{tabular}

stimulate or repress its transcription. Although it is difficult to directly relate the functions of most these specific transcription factors to recently observed carnitine effects in skeletal muscle, it is likely that carnitine mediates at least some of its effects on gene expression through regulating transcription factor activities by altering miRNA expression. The observation that the minor part of the transcription factors targeted by the carnitine-regulated miRNAs were general transcription factors, like GTF2B, GTF2I, HMGB2, MED14, MED17,

Table 4 Validation of predicted target-mRNAs using qRT-PCR

\begin{tabular}{|c|c|c|c|}
\hline Predicted target mRNAs & Related miRNA & Obese control & Obese carnitine \\
\hline & & \multicolumn{2}{|c|}{ Fold of control } \\
\hline & Up-regulated miRNAs & & \\
\hline WNT5A & miR-10b-5p & $1.00 \pm 0.57$ & $0.80 \pm 0.46$ \\
\hline UBE2A & miR-223-3p & $1.00 \pm 0.48$ & $0.52 \pm 0.10^{*}$ \\
\hline HERC2 & miR-208a-5p & $1.00 \pm 0.07$ & $0.87 \pm 0.08^{*}$ \\
\hline ALCAM & miR-434-3p & $1.00 \pm 0.13$ & $0.97 \pm 0.16$ \\
\hline ARPC5 & miR-190a-5p & $1.00 \pm 0.18$ & $0.73 \pm 0.14^{*}$ \\
\hline GNAI2 & miR-30d-5p & $1.00 \pm 0.14$ & $0.72 \pm 0.07^{*}$ \\
\hline FADS1 & miR-347 & $1.00 \pm 0.44$ & $0.86 \pm 0.11$ \\
\hline PIAS1 & miR-493-5p & $1.00 \pm 0.50$ & $1.02 \pm 0.59$ \\
\hline CBLB & miR-29a-5p & $1.00 \pm 0.46$ & $0.91 \pm 0.25$ \\
\hline SAMD4B & miR-451-5p & $1.00 \pm 0.38$ & $0.98 \pm 0.27$ \\
\hline \multirow[t]{2}{*}{ WSB1 } & miR-190b-5p & $1.00 \pm 0.41$ & $0.67 \pm 0.22$ \\
\hline & Down-regulated miRNAs & & \\
\hline SLC6A8 & miR-466c-5p & $1.00 \pm 0.44$ & $2.34 \pm 0.52^{*}$ \\
\hline $\mathrm{ABCG} 1$ & miR-883-5p & $1.00 \pm 0.38$ & $1.08 \pm 0.26$ \\
\hline IGF-1 & miR-466b-1-3p & $1.00 \pm 0.28$ & $2.26 \pm 0.65^{*}$ \\
\hline ITPR1 & miR-21-3p & $1.00 \pm 0.29$ & $1.37 \pm 0.15^{*}$ \\
\hline ACSL3 & miR-3596c & $1.00 \pm 0.49$ & $2.11 \pm 0.87^{*}$ \\
\hline SALL3 & miR-3584-3p & $1.00 \pm 0.44$ & $6.32 \pm 2.47^{*}$ \\
\hline
\end{tabular}

Data are expressed as means $\pm S D$ and were presented as fold of the obese control group, which mean was set to $1 ; n=6$ rats/group. *Indicates significant difference to the obese control group $(P<0.05)$. 
A

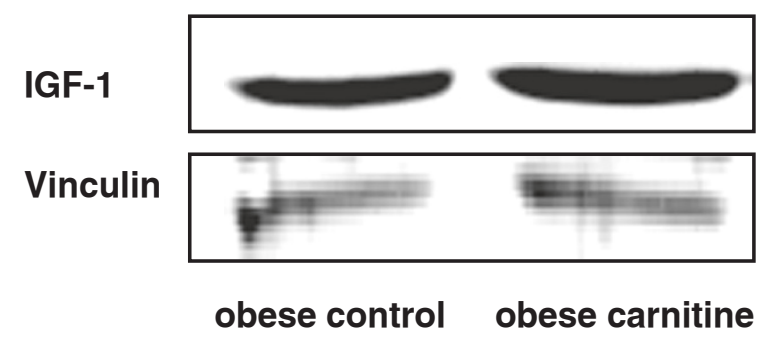

B

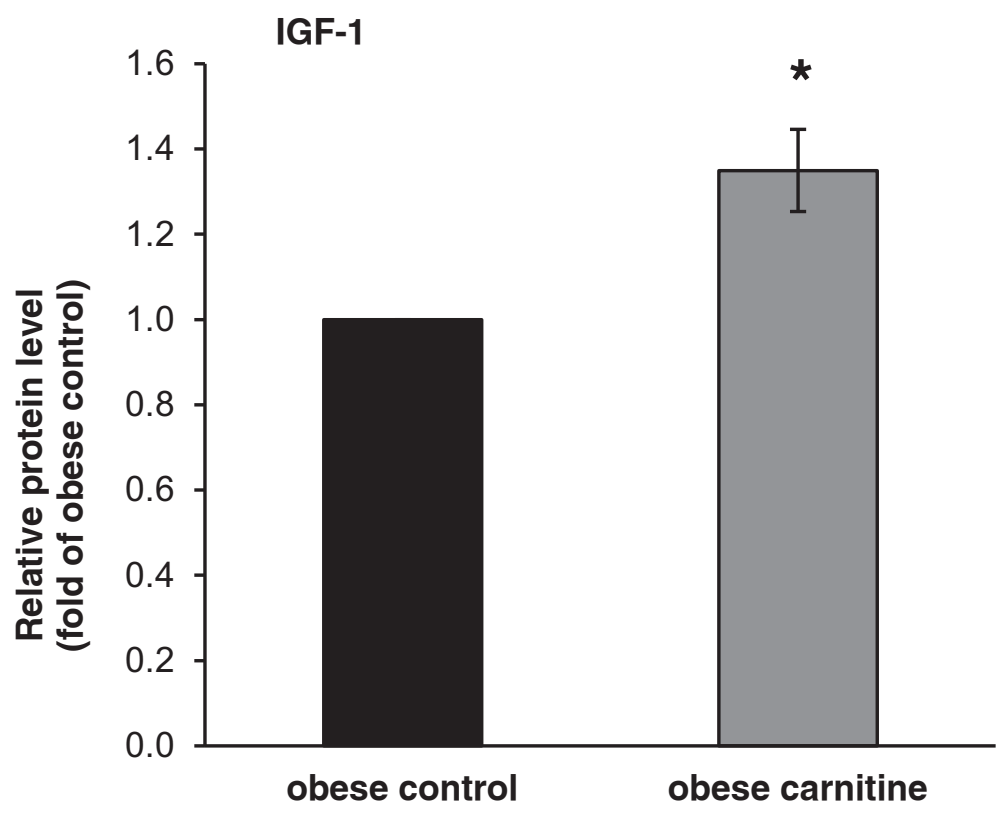

Figure 6 Relative protein level of IGF-1 in skeletal muscle of obese Zucker rats. (A) Representative immunoblots specific to IGF-1 and Vinculin as internal control are shown for one animal per group; immunoblots for the other animals revealed similar results. (B) Bars represent data from densitometric analysis and represent means \pm SD ( $n=6 /$ group); bars are expressed relative to the protein level of the obese control group (=1.00). *Indicates significant difference from the obese control group $(P<0.05)$.

and PAF1, does not exclude a significant involvement in inducing carnitine effects in skeletal muscle [7], because general transcription factors are essential for gene transcription to occur due to their obligatory role in transcription initiation by RNA polymerase II. Analysis of the involvement of the predicted target genes in specific KEGG pathways showed that particularly genes playing roles in signal transduction pathways, like the Wnt signalling pathway (e.g. WNT5A, TBL1XR1, TCF7, JUN, DKK2), long-term depression (e.g. IGF1, IGF1R, GNAI2 and PRKCB), and protein-degrading pathways, like ubiquitin-mediated proteolysis (e.g. UBE2A, UBE3A, VHL, UBA6, SMURF2), are targeted by the miRNAs regulated by carnitine supplementation. Regulation of miRNAs targeting genes belonging to ubiqutin-mediated proteolysis may provide a plausible explanation for our recent observations in rats and pigs that carnitine supplementation down-regulates key genes involved in ubiquitin-mediated proteolysis in skeletal muscle [9-11]. Ubiquitin-mediated proteolysis within proteasomes is the most important protein degradation pathway in tissues in general, and particularly responsible for the degradation of myofibrillar proteins in skeletal muscle which make up about $60 \%$ of total muscle proteins. Thus, the observation that carnitine supplementation reduces muscle wasting in a rat model of cancer cachexia [36], which is characterized by an increased activity of ubiquitin-mediated proteolysis, is largely explained by inhibition of this pathway. Inhibition of this pathway by carnitine supplementation is probably mediated by 
increasing plasma concentrations of IGF-1, which has been observed in several species including humans, pigs, rats and chickens [35,37-41]. IFG-1 is an important negative regulator of this protein degrading pathway and this effect is mediated by an activation of the PI3/Akt signalling pathway leading to inactivation of FoxO transcription factors and thereby inhibition of the ubiquitinligating E3 ligases [42]. Recently, we have indeed observed that carnitine supplementation activates the IGF-1/PI3K/Akt signalling pathway, inactivates FoxOs, reduces expression of E3 ligases and decreases the amount of ubiquitinated proteins which are targeted for degradation via the proteasome [11]. Moreover, since IGF-1 has also prominent functions in cell proliferation and differentiation it was not surprising that enrichment analysis identified IGF-1 as one gene involved in the KEGG pathways "pathways in cancer" but also in "longterm depression", that was targeted by the miRNAs down-regulated by carnitine supplementation. Thus, our observations indicate that the recently observed increases in mRNA and/or protein levels of IGF-1 following carnitine supplementation is mediated at the level of miRNA-mRNA interactions.

The large number of target genes (about 1,500) predicted from the most strongly regulated miRNAs and the other not explicitly mentioned data from gene-term enrichment analysis for the targets identified shows that carnitine supplementation may cause several other biological effects than up-regulation of IGF-1 or inhibition of ubiquitin-mediated proteolysis via miRNA-mRNA interactions. However, the biological implications of most of the observed carnitine-mediated changes in the miRNA expression profile and its impact on specific metabolic and signalling pathways and whole metabolism cannot be resolved with certainty using biostatistics tools alone, because the prediction of target genes from differentially expressed miRNAs is only an in silico-approach and, thus, has clear limitations. Therefore, time-consuming experimental studies with cultured muscle cells, in which the effect of carnitine in the presence of miRNA-specific inhibitors or during over-expression or knockdown of specific miRNAs on target gene expression is studied, are necessary in the future to validate at least some of the carnitine-mediated miRNA-mRNA interactions. Given that most of the detectable miRNAs (152 out of 259) were regulated by carnitine, it would be interesting to investigate in a future time-course experiment whether there are early and late responding miRNAs which behave differently to carnitine supplementation.

\section{Conclusions}

The present study clearly shows for the first time that a large set of miRNAs in skeletal muscle of obese Zucker rats are responsive to carnitine supplementation suggesting a novel mechanism through which carnitine exerts its multiple effects on gene expression. Using biostatistics tools at least some of the recently reported effects of carnitine supplementation on gene expression (IGF-1, E3 ligases) could be demonstrated to be likely mediated via miRNAmRNA interactions. Although the biological implications of most of the observed carnitine-mediated changes in the miRNA expression profile cannot be predicted using this biostatistics approach alone and experimental validations of miRNA-mRNA interactions are necessary, our results indicate that carnitine supplementation exerts several other biological effects through altering the expression of miRNAs.

\section{Methods}

\section{Animal experiment}

The animal experiment was approved by the local Animal Care and Use Committee. For this study, we used plasma and muscle samples from 6 obese Zucker rats per group from a previous experiment [30]. In this experiment, 8 to 10 week old, male obese $(f a / f a)$ Zucker rats (Crl:ZUC-Lepr ${ }^{f a}$; Charles River, France) were randomly divided in two groups (obese control group and obese carnitine group) and fed semi-purified diets according to the recommendations of the American Institute of Nutrition (AIN)-93G [43] ad libitum for 28 days. The treatment duration was based on several reports in the literature that carnitine supplementation improves carnitine status and causes profound changes in gene expression in different tissues within a few weeks [7]. The obese carnitine group received the same diet supplemented with $3 \mathrm{~g}$ carnitine $/ \mathrm{kg}$ diet. Blood was collected and plasma obtained by centrifugation, and skeletal muscle ( $M$. rectus femoris) was excised and immediately stored at $-80^{\circ} \mathrm{C}$. A detailed description of the animal experiment and sample collection can be found in our previous publication [30].

\section{Carnitine analysis}

Concentrations of free carnitine and acetyl carnitine in plasma and muscle were determined by tandem mass spectrometry using deuterated carnitine- $\mathrm{d}_{3}$ as internal standard as described recently in detail [44]. Concentration of total carnitine was calculated as the sum of free and acetyl carnitine.

\section{RNA isolation}

For miRNA microarray and qRT-PCR analysis total RNA, including small RNAs, was isolated from muscle samples using the Qiagen miRNeasy Mini Kit (Qiagen, Hilden, Germany), according to the manufacturer's protocol. Afterwards, the concentration of the RNA was determined using an Infinite $200 \mathrm{M}$ microplate reader and a nanoQuant Plate (both from Tecan, Männedorf, 
Switzerland) and its integrity was confirmed by agarose gel electrophoresis. Isolated RNA samples were immediately frozen and stored at $-80^{\circ} \mathrm{C}$.

\section{miRNA microarray analysis}

All microarray analyses were conducted at Exiqon Services (Denmark). Sample total RNA quality was verified using an Agilent BioAnalyzer 2100 System. MiRCURY LNA $^{\text {mit }}$ microRNA Arrays (7th Gen) following the miRBASE release 18 (http://www.mirbase.org/) were used to analyze the expression profile of each sample (Exiqon, Denmark). Briefly, $750 \mathrm{ng}$ total RNA from both sample and reference was labeled using the mercury LNA microRNA Hi-Power Labeling Kit, $\mathrm{Hy}^{\mathrm{mm}} / \mathrm{Hy}^{\mathrm{mx}}$ (Exiqon, Denmark) and were mixed pair-wise and hybridized according to the instruction manual using a Tecan HS4800 $^{\text {ma }}$ hybridization station (Tecan, Austria). Afterwards, slides were scanned using the Agilent G2565BA Microarray scanner System (Agilent Technologies, Inc., USA) and image analysis was carried out using the ImaGene $^{\circ} 9$ (mercury LNA ${ }^{\text {tw }}$ microRNA Array Analysis Software, Exiqon, Denmark). The quantified signals were background corrected (Normexp with offset value 10, see [45]) and normalized using the global Lowess (LOcally WEighted Scatterplot Smoothing) regression algorithm. The signal values were filtered based on absent/ present calls. miRNAs with present calls $<20 \%$ were removed from the final dataset used for the expression analysis. The microarray data related to all samples have been deposited in NCBI's Gene Expression Omnibus public repository [46].

\section{qRT-PCR validation of differentially expressed miRNAs}

qRT-PCR reactions were performed using a Rotor-Gene 2000 system (Corbett Research, Mortlake, Australia) to validate the expression of 21 miRNAs, which showed significant differences in their expression level with an adjusted $\mathrm{P}<0.05$ in the microarray experiment. For this end, $0.5 \mu \mathrm{g}$ of total RNA (RNA templates were the same as used for microarray hybridizations) were reverse transcribed using the miScript II RT Kit (Qiagen, Hilden, Germany), according the manufacturer's protocol and was stored in diluted (1:10) aliquots at $-20^{\circ} \mathrm{C} .2 \mu \mathrm{l}$ cDNA, $2 \mu \mathrm{l}$ each of miScript Universal Primer (10x) and miScript Primer Assay (10x) and $4 \mu \mathrm{l}$ RNase free water were added to $10 \mu \mathrm{l}$ QuantiTect SYBR Green PCR Master Mix (2x) (all from Qiagen, Hilden, Germany). The qRT-PCR cycle comprised of, 15-minute incubation at $95^{\circ} \mathrm{C}$ followed by 40 cycles of a three-stage temperature profile of $94^{\circ} \mathrm{C}$ for $15 \mathrm{sec}$ and $55^{\circ} \mathrm{C}$ for $30 \mathrm{sec}$ and final $70^{\circ} \mathrm{C}$ for $30 \mathrm{sec}$. The relative changes of each transcript were calculated by using the the $2^{-\Delta \mathrm{Ct}}$ equation [47] with the expression level of U6 snRNA (U6 small nuclear RNA) as an internal control.

\section{Prediction of targets of differentially expressed microRNAs and functional analysis}

Prediction of putative miRNA targets was performed by using three online free available algorithms TargetScan release version 6.2 (http://www.targetscan.org/), miRanda and miRDB (http://mirdb.org/miRDB/). To identify enriched (overrepresented) Gene Ontology (GO) terms and Kyoto Encyclopedia of Genes and Genomes (KEGG) pathways for the target genes of the differentially expressed miRNAs, we used the Database for Annotation, Visualization and Integrated Discovery (DAVID) gene annotation tool [48].

\section{qRT-PCR validation of selected potential target genes}

qRT-PCR analysis of predicted target genes and reference genes as well as calculation of gene expression data was performed as described recently in detail [10]. The normalization factor was calculated as the geometric mean of expression data of the three most stable out of six tested potential reference genes (CANX, MDH1, ACTB, RPL13, TOP1, and ATP5B). The three most stable reference genes were (the stability score $\mathrm{M}$ as calculated by GeNorm is shown in brackets): CANX (0.025), TOP1 (0.030) and RPL13 (0.036). Means and SD were calculated from normalized expression data for samples of the same treatment group. The mean of the obese control group was set to 1 and mean and SD of the obese carnitine group were scaled proportionally. Features of genespecific primer pairs are listed in Table 5.

\section{Western Blotting}

For western blot analysis, frozen muscle samples $(30 \mathrm{mg})$ were homogenized in RIPA buffer (radioimmunoprecipitation assay buffer; $50 \mathrm{mM}$ Tris, $150 \mathrm{mM} \mathrm{NaCl}, 10 \%$ glycerol, $0.1 \%$ SDS, $1 \%$ Triton X-100, 1 mM EDTA, 0.5\% deoxycholate, $1 \%$ protease inhibitor mix; $\mathrm{pH}$ 7.5) using an Ultraturrax (IKA Werke GmbH, Staufen, Germany). The homogenate was centrifuged at $16,200 \mathrm{~g}\left(4^{\circ} \mathrm{C}\right)$ for 15 min. Protein concentrations were determined in the supernatants using the bicinchoninic acid protein assay kit (Interchim, Montluçon, France) with BSA as standard. Subsequently, equal amounts $(50 \mu \mathrm{g})$ of protein samples were separated on 12.5\% SDS-PAGE and electrotransferred to a nitrocellulose membrane (Pall Corporation, Pensacola, FL, USA). Loading of equal amounts of protein in each line was verified by Ponceau S (Carl Roth, Karlsruhe, Germany) staining. After incubation the membranes overnight at $4{ }^{\circ} \mathrm{C}$ in blocking solution (5\% nonfat dried milk powder), membranes were incubated with primary antibodies against IGF-1 (polyclonal anti-IGF-1 antibody; Santa Cruz Biotechnology, Inc., Santa Cruz, Ca, USA) and Vinculin (monoclonal anti-Vinculin antibody; Invitrogen Corporation, CA, USA) as a reference protein for normalization. The membranes were washed, and then 
Table 5 Characteristics of specific primers used for validation of target-mRNAs by qRT-PCR

\begin{tabular}{|c|c|c|c|c|c|}
\hline Gene & Forward Primer $\left(3^{\prime}-5^{\prime}\right)$ & Reverse Primer $\left(3^{\prime}-5^{\prime}\right)$ & Product length (bp) & $\mathrm{T}_{\mathrm{m}}\left({ }^{\circ} \mathrm{C}\right)$ & NCBI GenBank \\
\hline \multicolumn{6}{|c|}{ Reference genes } \\
\hline ACTB & GACCTCTATGCCAACACAGT & CACCAATCCACACAGAGTAC & 154 & 60 & NM_031144.2 \\
\hline ATP5B & GCACCGTCAGAACTATTGCT & GAATTCAGGAGCCTCAGCAT & 203 & 60 & NM_134364.1 \\
\hline CANX & CCAGATGCAGATCTGAAGAC & CTGGGTCCTCAATTTCACGT & 175 & 60 & NM_172008.2 \\
\hline $\mathrm{MDH} 1$ & CAGACAAAGAAGAGGTTGCC & CGTCAGGCAGTTTGTATTGG & 206 & 60 & NM_033235.1 \\
\hline RPL13 & CTTAAATTGGCCACGCAGCT & CTTCTCAACGTCTTGCTCTG & 198 & 60 & NM_031101.1 \\
\hline TOP1 & GAAGAACGCTATCCAGAAGG & GCTITGGGACTCAGCTTCAT & 137 & 60 & NM_022615.1 \\
\hline \multicolumn{6}{|c|}{ Target genes } \\
\hline$A B C G 1$ & GCCATCCCTGTCTTGCTCTT & TCCTCTCGGTCCAAGCCATA & 143 & 56 & NM_053502.1 \\
\hline ACSL3 & GTAAAACTTGATTCCCGTTGAGA & GTGTCGCAGCCAGGATACA & 307 & 60 & NM_057107.1 \\
\hline ALCAM & TCGCTGACCCTCATCGTAGA & ATCGTCTGCCTCATCGTGTT & 321 & 60 & NM_031753.1 \\
\hline ARPC5 & GGGATGTCGAAGAACACGGT & GTAGGCATGAGTCCACCTCG & 142 & 60 & NM_001025717.1 \\
\hline CBLB & TTGAAGGGTGAAGATGCTTTGAT & ACTGGAGCCTGGAGGTTTTG & 105 & 60 & NM_133601.1 \\
\hline FADS1 & CCACTACGCTGGTCAGGATG & AGCGCCTTATTCTTGGTGGG & 144 & 60 & NM_053445.2 \\
\hline GNAI2 & GCCGAGCGCTCTAAGATGAT & TGCTTGACGATGGTGCTCTT & 119 & 60 & NM_031035.3 \\
\hline HERC2 & CCTGACCACCGAGAGGAAAC & ACACCATCATCTGGATATCTGTT & 102 & 60 & NM_001107520.1 \\
\hline IGF-1 & CCCGGGACGTACCAAAATGAGCG & ATGTCAGTGTGGCGCTGGGC & 354 & 64 & NM_001082477.2 \\
\hline ITPR1 & ATGCCAGGAGGAAATGCGAA & CTCAGGGGTGGACTTGGTTC & 250 & 60 & NM_006236992.1 \\
\hline PIAS1 & ATGACCTGCTGGACGAACTG & ACTGTCGTGGACAATCGGAC & 355 & 60 & NM_001106829.2 \\
\hline SALL3 & CTCTTCTTGGTTTCCTAGGCGT & TCCGCCCACTTGAAGAACTC & 130 & 60 & NM_001108892.1 \\
\hline SAMD4B & TGTGGACCTCCCCTGCTTTG & GAGCAAAGGCACAGAAACCTG & 199 & 60 & NM_001107498.1 \\
\hline SLC6A8 & GGTCCCCTGTCATCGAGTTC & GAGGACCACGTAGGGGAATG & 197 & 60 & NM_017348.2 \\
\hline UBE2A & TGTGGAAACCACAGGACAACT & CAGTCACGCCAGCTTTGTTC & 327 & 60 & NM_001013933.1 \\
\hline WNT5A & TCCGCAGTCCTGCTTTGAAT & CAAAGCCACTCCTGGGCTTA & 156 & 60 & NM_022631.1 \\
\hline WSB1 & GAGTTCCCGGAATCAGACGG & CCGGAGCAAAAGCAACAGTC & 163 & 60 & NM_00104256.1 \\
\hline
\end{tabular}

incubated with a horseradish peroxidase conjugated secondary polyclonal anti-rabbit-IgG antibody (SigmaAldrich, Steinheim, Germany) at RT. Afterwards blots were developed using ECL Plus or ECL Advanced (both GE Healthcare, Munich, Germany). The signal intensities of specific bands were detected with a Bio-Imaging system (Syngene, Cambridge, UK) and quantified using Syngene GeneTools software (nonlinear dynamics).

\section{Statistical analysis}

Values presented in the text are means \pm SD. Data were analyzed by Student's $t$ test with dietary carnitine concentration as factor using the Minitab statistical software (Release 13, Minitab Inc., State College, PA, USA). Means were considered significantly different at $\mathrm{P}<0.05$. P-values of microarray data have been corrected for multiple testing by the Benjamini and Hochberg adjustment method. miRNAs with an adjusted P-value $<0.05$ were considered to be differentially expressed miRNAs by carnitine supplementation. Subsequently, genes found to be significant by the one-way ANOVA test have been subjected to the Tukey's 'Honest Significant Difference' test to determine which groups contribute most to the significant difference.

\section{Availability of supporting data}

The microarray data set supporting the results of this article is available in the Gene Expression Omnibus repository, GEO Series accession number GSE58537, http:// www.ncbi.nlm.nih.gov/geo/query/acc.cgi?acc=GSE58537.

\section{Additional files}

Additional file 1: Differentially expressed miRNAs by supplementa carnitine in skeletal muscle of obese Zucker rats. Spreadsheet contains all differentially expressed miRNAs by carnitine with an adjusted P-value $<0.05$.

Additional file 2: Predicted target genes of the 17 validated, most differentially expressed miRNAs by supplemental carnitine in skeletal muscle of obese Zucker rats. Spreadsheet contains target genes of the validated 11 up- and 6 down-regulated miRNAs by supplemental carnitine predicted by at least one and a maximum of three online free available algorithms TargetScan, miRanda and miRDB. 


\section{Abbreviations}

miRNA: microRNA; qRT-PCR: Quantitative real time-polymerase chain reaction; IGF-1: Insulin like growth factor 1; GO: Gene ontology; KEGG: Kyoto encyclopedia of genes and genomes.

\section{Competing interests}

The authors declare that they have no competing interests.

\section{Authors' contributions}

JK and KE designed research and coordinated the study. JK carried out the molecular biological analyses. JK, RR and KE wrote the paper. All authors read and approved the final manuscript.

\section{Acknowledgements}

Janine Keller is financed by the Deutsche Forschungsgemeinschaft (DFG; Germany). The authors are very grateful to Erika Most for carnitine analytics.

Received: 12 November 2013 Accepted: 17 June 2014 Published: 21 June 2014

\section{References}

1. Kerner J, Hoppel C: Fatty acid import into mitochondria. Biochim Biophys Acta 2000, 1486:1-17.

2. Owen KQ, Nelssen JL, Goodband RD, Weeden TL, Blum SA: Effect of $\mathrm{L}$-carnitine and soybean oil on growth performance and body composition of early-weaned pigs. J Anim Sci 1996, 74:1612-1619.

3. Musser RE, Goodband RD, Tokach MD, Owen KQ, Nelssen JL, Blum SA, Dritz SS, Civis CA: Effects of L-carnitine fed during gestation and lactation on sow and litter performance. J Anim Sci 1999, 77:3289-3295.

4. Heo K, Odle J, Han IK, Cho W, Seo S, van Heugten E, Pilkington DH: Dietary L-carnitine improves nitrogen utilization in growing pigs fed low energy, fat-containing diets. J Nutr 2000, 130:1809-1814

5. Eder K, Ramanau A, Kluge H: Effect of L-carnitine supplementation on performance parameters in gilts and sows. J Anim Physiol Anim Nutr (Berl) 2001, 85:73-80.

6. Ramanau A, Kluge H, Spilke J, Eder K: Reproductive performance of sows supplemented with dietary L-carnitine over three reproductive cycles. Arch Tierernahr 2002, 56:287-296.

7. Ringseis R, Keller J, Eder K: Role of carnitine in the regulation of glucose homeostasis and insulin sensitivity: evidence from in vivo and in vitro studies with carnitine supplementation and carnitine deficiency. Eur J Nutr 2012, 51:1-18.

8. Keller J, Ringseis R, Priebe S, Guthke R, Kluge H, Eder K: Effect of L-carnitine on the hepatic transcript profile in piglets as animal model. Nutr Metab (Lond) 2011, 8:76.

9. Keller J, Ringseis R, Priebe S, Guthke R, Kluge H, Eder K: Dietary L-carnitine alters gene expression in skeletal muscle of piglets. Mol Nutr Food Res 2011, 55:419-429.

10. Keller J, Ringseis R, Koc A, Lukas I, Kluge H, Eder K: Supplementation with I-carnitine downregulates genes of the ubiquitin proteasome system in the skeletal muscle and liver of piglets. Animal 2012, 6:70-78.

11. Keller J, Couturier A, Haferkamp M, Most E, Eder K: Supplementation of carnitine leads to an activation of the IGF-1/PI3K/Akt signalling path way and down regulates the E3 ligase MuRF1 in skeletal muscle of rats. Nutr Metab (Lond) 2013, 10:28

12. Ambros $V$ : The functions of animal microRNAs. Nature 2004, 431:350-355.

13. Bartel DP: MicroRNAs: genomics, biogenesis, mechanism, and function. Cell 2004, 2004(116):281-297.

14. Qin W, Shi Y, Zhao B, Yao C, Jin L, Ma J, Jin Y: miR-24 regulates apoptosis by targeting the open reading frame (ORF) region of FAF1 in cancer cells. PLoS One 2010, 5:e9429.

15. Shivdasani RA: MicroRNAs: regulators of gene expression and cell differentiation. Blood 2006, 108:3646-3653.

16. Grimson A, Farh KK, Johnston WK, Garrett-Engele P, Lim LP, Bartel DP: MicroRNA targeting specificity in mammals: determinants beyond seed pairing. Mol Cell 2007, 27:91-105.

17. Filipowicz W, Bhattacharyya SN, Sonenberg N: Mechanisms of posttranscriptional regulation by microRNAs: are the answers in sight? Nat Rev Genet 2008, 9:102-114.

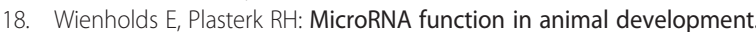
FEBS Lett 2005, 579:5911-5922.
19. Wu L, Fan J, Belasco JG: MicroRNAs direct rapid deadenylation of mRNA. Proc Natl Acad Sci U S A 2006, 103:4034-4039.

20. Ørom UA, Nielsen FC, Lund AH: MicroRNA-10a binds the 5'UTR of ribosomal protein mRNAs and enhances their translation. Mol Cell 2008, 30:460-471

21. Krek A, Grün D, Poy MN, Wolf R, Rosenberg L, Epstein EJ, MacMenamin P, da Piedade I, Gunsalus KC, Stoffel M, Rajewsky N: Combinatorial microRNA target predictions. Nat Genet 2005, 37:495-500.

22. Lewis BP, Burge CB, Bartel DP: Conserved seed pairing, often flanked by adenosines, indicates that thousands of human genes are microRNA targets. Cell 2005, 120:15-20.

23. Cheng Y, Ji R, Yue J, Yang J, Liu X, Chen H, Dean DB, Zhang C: MicroRNAs are aberrantly expressed in hypertrophic heart: do they play a role in cardiac hypertrophy? Am J Pathol 2007, 170:1831-1840.

24. Ikeda S, Kong SW, Lu J, Bisping E, Zhang H, Allen PD, Golub TR, Pieske B, Pu WT: Altered microRNA expression in human heart disease. Physiol Genomics 2007, 31:367-373.

25. Zhang B, Pan $X$, Cobb GP, Anderson TA: microRNAs as oncogenes and tumor suppressors. Dev Biol 2007, 302:1-12.

26. Yildirim SS, Akman D, Catalucci D, Turan B: Relationship between downregulation of miRNAs and increase of oxidative stress in the development of diabetic cardiac dysfunction: junctin as a target protein of miR-1. Cell Biochem Biophys 2013, 67:1397-1408.

27. Shen H, Liu T, Fu L, Zhao S, Fan B, Cao J, Li X: Identification of microRNAs involved in dexamethasone-induced muscle atrophy. Mol Cell Biochem 2013, 381:105-113.

28. Karere GM, Glenn JP, VandeBerg $J$, Cox LA: Differential microRNA response to a high-cholesterol, high-fat diet in livers of low and high LDL-C baboons. BMC Genomics 2012, 13:320.

29. Parra P, Serra F, Palou A: Expression of adipose microRNAs is sensitive to dietary conjugated linoleic acid treatment in mice. PLoS One 2010, 5:e13005.

30. Couturier A, Ringseis R, Mooren FC, Krüger K, Most E, Eder K: Carnitine supplementation to obese Zucker rats prevents obesity-induced type II to type I muscle fiber transition and favors an oxidative phenotype of skeletal muscle. Nutr Metab (Lond) 2013, 10:48

31. Koves TR, Ussher JR, Noland RC, Slentz D, Mosedale M, Ilkayeva O, Bain J, Stevens R, Dyck JR, Newgard CB, Lopaschuk GD, Muoio DM: Mitochondrial overload and incomplete fatty acid oxidation contribute to skeletal muscle insulin resistance. Cell Metab 2008, 7:45-56.

32. Noland RC, Koves TR, Seiler SE, Lum H, Lust RM, Ilkayeva O, Stevens RD, Hegardt FG, Muoio DM: Carnitine insufficiency caused by aging and overnutrition compromises mitochondrial performance and metabolic control. J Biol Chem 2009, 284:22840-22852.

33. Ringseis R, Mooren FC, Keller J, Couturier A, Wen G, Hirche F, Stangl Gl, Eder K, Krüger K: Regular endurance exercise improves the diminished hepatic carnitine status in mice fed a high-fat diet. Mol Nutr Food Res 2011, 55(Suppl 2):193-202.

34. Power RA, Hulver MW, Zhang JY, Dubois J, Marchand RM, Ilkayeva O, Muoio DM, Mynatt RL: Carnitine revisited: potential use as adjunctive treatment in diabetes. Diabetologia 2007, 50:824-832.

35. Heo YR, Kang CW, Cha YS: L-Carnitine changes the levels of insulin-like growth factors (IGFs) and IGF binding proteins in streptozotocin-induced diabetic rat. J Nutr Sci Vitaminol (Tokyo) 2001, 47:329-334.

36. Busquets S, Serpe R, Toledo M, Betancourt A, Marmonti E, Orpí M, Pin F, Capdevila E, Madeddu C, López-Soriano FJ, Mantovani G, Macciò A, Argilés JM: L-Carnitine: an adequate supplement for a multi-targeted antiwasting therapy in cancer. Clin Nutr 2012, 31:889-895.

37. Di Marzio L, Moretti S, D'Alò S, Zazzeroni F, Marcellini S, Smacchia C, Alesse E, Cifone MG, De Simone C: Acetyl-L-carnitine administration increases insulin-like growth factor 1 levels in asymptomatic HIV-1-infected subjects: correlation with its suppressive effect on lymphocyte apoptosis and ceramide generation. Clin Immunol 1999, 92:103-110.

38. Kita K, Kato S, Amanyaman M, Okumura J, Yokota H: Dietary L-carnitine increases plasma insulin-like growth factor-I concentration in chicks fed a diet with adequate dietary protein level. Br Poult Sci 2002, 43:117-121.

39. Doberenz J, Birkenfeld C, Kluge H, Eder K: Effects of L-carnitine supplementation in pregnant sows on plasma concentrations of insulin-like growth factors, various hormones and metabolites and chorion characteristics. J Anim Physiol Anim Nutr (Berl) 2006, 90:487-499.

40. Woodworth JC, Tokach MD, Nelssen JL, Goodband RD, Dritz SS, Koo SI, Minton JE, Owen KQ: Influence of dietary L-carnitine and chromium 
picolinate on blood hormones and metabolites of gestating sows fed one meal per day. J Anim Sci 2007, 85:2524-2537.

41. Brown KR, Goodband RD, Tokach MD, Dritz SS, Nelssen JL, Minton JE, Higgins JJ, Lin X, Odle J, Woodworth JC, Johnson BJ: Effects of feeding L-carnitine to gilts through day 70 of gestation on litter traits and the expression of insulin-like growth factor system components and L-carnitine concentration in foetal tissues. J Anim Physiol Anim Nutr (Berl) 2008, 92:660-667.

42. Brunet $\mathrm{A}$, Bonni A, Zigmond MJ, Lin MZ, Juo P, Hu LS, Anderson MJ, Arden KC, Blenis J, Greenberg ME: Akt promotes cell survival by phosphorylating and inhibiting a Forkhead transcription factor. Cell 1999, 96:857-868.

43. Reeves PG, Nielsen FH, Fahey GC: AIN-93 purified diets for laboratory rodents: final report of the American Institute of Nutrition ad hoc writing committee on the reformulation of the AIN-76A rodent diet. J Nutr 1993, 123:1939-1951.

44. Hirche F, Fischer M, Keller J, Eder K: Determination of carnitine, its short chain acyl esters and metabolic precursors trimethyllysine and gamma-butyrobetaine by quasi-solid phase extraction and MS/MS detection. J Chromatogr B Analyt Technol Biomed Life Sci 2009, 877:2158-2162.

45. Ritchie ME, Silver J, Oshlack A, Holmes M, Diyagama D, Holloway A, Smyth GK: A comparison of background correction methods for two-colour microarrays. Bioinformatics 2007, 23:2700-2707.

46. Edgar R, Domrachev M, Lash AE: Gene Expression Omnibus: NCBI gene expression and hybridization array data repository. Nucleic Acids Res 2002, 30:207-210.

47. Livak KJ, Schmittgen TD: Analysis of relative gene expression data using real-time quantitative PCR and the 2(-Delta Delta $C(T)$ ) Method. Methods 2001, 25:402-408.

48. da Huang W, Sherman BT, Lempicki RA: Systematic and integrative analysis of large gene lists using DAVID bioinformatics resources. Nat Protoc 2009, 4:44-57.

doi:10.1186/1471-2164-15-512

Cite this article as: Keller et al:: Supplemental carnitine affects the microRNA expression profile in skeletal muscle of obese Zucker rats. BMC Genomics 2014 15:512.

\section{Submit your next manuscript to BioMed Central and take full advantage of:}

- Convenient online submission

- Thorough peer review

- No space constraints or color figure charges

- Immediate publication on acceptance

- Inclusion in PubMed, CAS, Scopus and Google Scholar

- Research which is freely available for redistribution 